\title{
Extracellular Lipids Accumulate in Human Carotid Arteries as Distinct Three-Dimensional Structures and Have Proinflammatory Properties
}

\author{
Satu Lehti, ${ }^{*}$ Su D. Nguyen, ${ }^{*}$ Ilya Belevich, ${ }^{\dagger}$ Helena Vihinen, ${ }^{\dagger}$ Hanna M. Heikkilä, ${ }^{\ddagger}$ Rabah Soliymani, ${ }^{\S}$ Reijo Käkelä, ${ }^{\top}$ Jani Saksi,

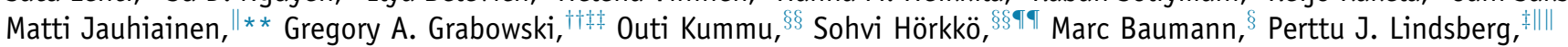 \\ Eija Jokitalo, ${ }^{\dagger}$ Petri T. Kovanen, ${ }^{*}$ and Katariina Öörni* ${ }^{*}$
}

\begin{abstract}
From the Atherosclerosis Research Laboratory, ${ }^{*}$ Wihuri Research Institute, Helsinki, Finland; the Electron Microscopy Unit, ${ }^{\dagger}$ Institute of Biotechnology, Molecular Neurology, ${ }^{\ddagger}$ Research Programs Unit, Clinical Proteomics Core Facility, ${ }^{\S}$ Medicum-Biochemistry and Developmental Biology, School of Medicine, and Helsinki University Lipidomics Unit, ${ }^{\Uparrow}$ Department of Biosciences, University of Helsinki, Helsinki, Finland; the National Institute for Health and Welfare," Helsinki, Finland; the Minerva Foundation Institute for Medical Research,** Helsinki, Finland; Cincinnati Children's Hospital Medical Center,${ }^{\dagger \dagger}$ Cincinnati, Ohio; Kiniksa Pharmaceuticals, Ltd.. ${ }^{\ddagger \dagger}$ Wellesley, Massachusetts; Medical Microbiology and Immunology, ${ }^{\S 5}$ Research Unit of

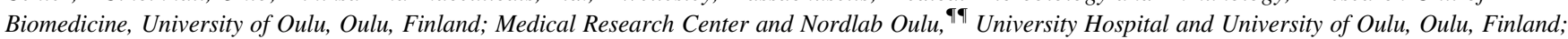
and Clinical Neurosciences, Neurology, ${ }^{\|\|}$University of Helsinki and Helsinki University Hospital, Helsinki, Finland
\end{abstract}

\author{
Accepted for publication \\ September 26, 2017. \\ Address correspondence to \\ Katariina Öörni, Ph.D., \\ Atherosclerosis Research Lab- \\ oratory, Wihuri Research Insti- \\ tute, Haartmaninkatu 8, 00290 \\ Helsinki, Finland. E-mail: kati. \\ oorni@wri.fi.
}

\begin{abstract}
Lipid accumulation is a key characteristic of advancing atherosclerotic lesions. Herein, we analyzed the ultrastructure of the accumulated lipids in endarterectomized human carotid atherosclerotic plaques using three-dimensional (3D) electron microscopy, a method never used in this context before. 3D electron microscopy revealed intracellular lipid droplets and extracellular lipoprotein particles. Most of the particles were aggregated, and some connected to needle-shaped or sheet-like cholesterol crystals. Proteomic analysis of isolated extracellular lipoprotein particles revealed that apolipoprotein B is their main protein component, indicating their origin from low-density lipoprotein, intermediate-density lipoprotein, very-low-density lipoprotein, lipoprotein (a), or chylomicron remnants. The particles also contained small exchangeable apolipoproteins, complement components, and immunoglobulins. Lipidomic analysis revealed differences between plasma lipoproteins and the particles, thereby indicating involvement of lipolytic enzymes in their generation. Incubation of human monocyte-derived macrophages with the isolated extracellular lipoprotein particles or with plasma lipoproteins that had been lipolytically modified in vitro induced intracellular lipid accumulation and triggered inflammasome activation in them. Taken together, extracellular lipids accumulate in human carotid plaques as distinct 3D structures that include aggregated and fused lipoprotein particles and cholesterol crystals. The particles originate from plasma lipoproteins, show signs of lipolytic modifications, and associate with cholesterol crystals. By inducing intracellular cholesterol accumulation (ie, foam cell formation) and inflammasome activation, the extracellular lipoprotein particles may actively enhance atherogenesis. (Am J Pathol 2018, 188: 525-538; https://doi.org/10.1016/j.ajpath.2017.09.019)
\end{abstract}

Supported by the Academy of Finland grant 265940 (K.Ö.), the Finnish Foundation for Cardiovascular Research (S.L. and K.Ö.), Helsinki University Hospital research funds [Erityisvaltionosuus (EVO)] (H.M.H., J.S., and P.J.L.), and Biocenter Finland (I.B., H.V., and E.J.). The Wihuri Research Institute is maintained by the Jenny and Antti Wihuri Foundation.
Disclosures: G.A.G. serves as Chief Scientific Officer of Kiniksa Pharmaceuticals, Ltd. (KPL), a privately held biotechnology company. He serves in this capacity under a consulting contract and is not an employee of KPL. He is also a founder, owns stock in, and has stock options from KPL. KPL is an immunology-based company and is not in the field of lysosomal acid lipase or other lysosomal diseases. 
Atherosclerosis underlies carotid artery disease, which is one of the leading causes of ischemic strokes. ${ }^{1}$ In carotid arteries, like in other atherosclerosis-susceptible arterial beds, circulating liver-derived apolipoprotein (apo)B-100-containing and gut-derived apoB-48-containing lipoprotein particles enter the arterial wall ${ }^{2}$ and may initiate and sustain the development of atherosclerotic lesions. The atherogenic lipoproteins capable of entering arterial intima, the site of atherogenesis, are very-low-density lipoprotein (VLDL) remnants, low-density lipoprotein (LDL) particles, and chylomicron remnants. ${ }^{3,4}$ In the intima, the particles bind to extracellular matrix proteoglycans via apoB or apoE. ${ }^{5-7}$

The retained lipoprotein particles are susceptible to a variety of modifications, such as proteolysis, lipolysis, and oxidation. $^{8}$ Indeed, lipoprotein particles isolated from atherosclerotic lesions show signs of these types of modifications. $^{9-12}$ Intimal macrophages, mast cells, and smooth muscle cells secrete various proteolytic, lipolytic, and oxidizing enzymes, and biologically active agents, many of which have been shown to be able to attack lipoprotein particles. These include cathepsins, ${ }^{13-16}$ matrix metalloproteinases, ${ }^{17}$ mast cell chymase, ${ }^{18,19}$ various forms of phospholipase $\mathrm{A}_{2}\left(\mathrm{PLA}_{2}\right)$, and secreted sphingomyelinase (SMase). ${ }^{20-24}$ More important, proteolyzed or oxidized LDL particles are more susceptible to lipolytic modifications, ${ }^{14,20,25}$ a finding that supports the concept of multiplymodified lipoprotein particles.

Modification of the LDL surface changes the conformation of apoB-100. ${ }^{26,27}$ Perturbations of the surface phospholipid monolayer also enable efficient hydrolysis of the cholesteryl esters (CEs) and triacylglycerols in the LDL core, thus causing transformation of LDL particles into liposomes and multilamellar vesicles. ${ }^{28}$ Indeed, the presence of cholesteryl esterase-modified LDL has been verified in atherosclerotic lesions. ${ }^{25}$ Because hydrolysis of CEs leads to the generation of unesterified cholesterol, the critical concentration of cholesterol may be surpassed, thus allowing nucleation of cholesterol crystals. ${ }^{29,30}$

Surface changes may lead to aggregation of lipoprotein particles. ${ }^{8}$ Aggregated and fused lipoproteins have a higher affinity for arterial proteoglycans than monomeric lipoproteins, promoting their retention within the extracellular matrix. ${ }^{31}$ In the intima, the modified and aggregated lipoprotein particles can also be taken up by macrophages or smooth muscle cells, which then gradually become foam cells. ${ }^{32,33}$ Uptake of modified LDL can also induce nucleation of cholesterol crystals in the lysosomes of the cells. ${ }^{34}$ Cholesterol crystals, whether taken up or generated within the lysosomes, have an ability to activate the nucleotide-binding domain leucine-rich repeat containing (NLR) family, pyrin domain containing 3 (NLRP3) inflammasome, ${ }^{35-37}$ a complex that regulates the generation of active caspase-1, which, again, catalyzes the cleavage of pro-IL-1 $\beta$ and pro-IL-18 into their biologically active secretable forms. The expression of several key inflammasome components has been shown to be increased in atherosclerotic lesions. ${ }^{38}$ In addition to cholesterol crystals, other lipids carried with modified LDL can induce inflammatory activation of macrophages. Of those lipids, lysophospholipids and, in the presence of glucose, unesterified fatty acids have been shown to induce IL- $1 \beta$ secretion by macrophages. ${ }^{39,40}$

In this study, the ultrastructure of the lipoprotein particles accumulated in advanced human atherosclerotic lesions was first examined in situ. This was conducted by analyzing samples of endarterectomized carotid atherosclerotic plaques by three-dimensional electron microscopy (3D-EM), a method not previously used in this context. The extracellular lipoprotein particles present in the plaques were then isolated and molecularly characterized; they were found to be metabolically relevant lipoprotein-derived structures, which can induce not only lipid accumulation but also inflammation in atherogenesis.

\section{Materials and Methods}

\section{Ethics Statement}

The use of human material conforms to the principles outlined in the Declaration of Helsinki, and the study protocol was approved by the local Medical Ethics Committee. All patients had signed an informed consent document. Human plasma and buffy coats were obtained from healthy blood donors (Finnish Red Cross Blood Service, Helsinki, Finland) who signed informed consent documents. The plasma samples were by-products from the preparation of blood products for clinical use. The use of the samples was approved by the Finnish Red Cross Blood Service.

\section{Carotid Artery Samples}

Atherosclerotic plaques from human external or common carotid arteries were acquired from patients undergoing carotid endarterectomy in the Department of Vascular Surgery, Helsinki University Hospital (Helsinki, Finland). Altogether, 322 tissue pieces, one per plaque, from 279 patients were cut from the endarterectomized carotid plaques and used in this study. Intimal pieces for immunohistochemistry (four plaques from four patients) or electron microscopy (six plaques from six patients, four of them the same as for immunohistochemistry) were fixed and processed immediately after the excision. Pieces intended for lipoprotein particle isolation and consequent analyses were frozen in liquid nitrogen and stored at $-80^{\circ} \mathrm{C}$ until use.

\section{D-EM}

The plaque pieces for 3D-EM were fixed with $2 \%$ formaldehyde and $2.5 \%$ glutaraldehyde, in $0.1 \mathrm{~mol} / \mathrm{L} \mathrm{Na}$-cacodylate buffer (pH 7.4) supplemented with $2 \mathrm{mmol} / \mathrm{L} \mathrm{CaCl}_{2}$ for 2 to 3 hours. The fixed samples were stored in $0.1 \mathrm{~mol} / \mathrm{L}$ Na-cacodylate-2 $\mathrm{mmol} / \mathrm{L} \mathrm{CaCl}_{2}$ buffer containing $2 \%$ of paraformaldehyde for stability and were further processed using 
a previously described protocol for enhanced contrast. ${ }^{41,42}$ Durcupan ACM resin (Merck Sigma-Aldrich, Darmstadt, Germany) was mixed, according to the manufacturer's recommendations. After dehydration and infiltration, samples were embedded in silicone holders filled with 100\% Durcupan and incubated for at least 2 hours before polymerization at $60^{\circ} \mathrm{C}$. A pyramid of tissue was trimmed and mounted onto a pin using conductive epoxy glue (model 2400; CircuitWorks, Kennesaw, GA) for serial block-face electron microscopy (SBEM). Finally, the sides of the pyramid were covered with silver paint (Agar Scientific Ltd, Stansted, UK), and the whole assembly was platinum coated using Quorum Q150TS (Quorum Technologies, Laughton, UK). SBEM data sets were acquired with an FEG-SEM Quanta 250 (FEI, Hillsboro, OR), using a backscattered electron detector (Gatan Inc., Pleasanton, $\mathrm{CA}$ ) with $2.5-\mathrm{kV}$ beam voltage, a spot size of 3 , and a pressure of 0.2 Torr. The block faces were cut with 40-nm increments and imaged with XY resolution of $20 \mathrm{~nm}$ per pixel.

For electron tomography, semithick sections $(250 \mathrm{~nm}$ thick) were cut from a trimmed pyramid using a Leica ultracut UCT ultramicrotome, and 10-nm colloidal gold particles were placed on top/below the section to serve as fiducial markers for the alignment. The dual-axis tilt series was recorded using a Tecnai FEG 20 transmission electron microscope (FEI) operating at $200 \mathrm{kV}$. Images were acquired using SerialEM software version 3.2.2 $2^{43}$ and a $4 \mathrm{~K} \times 4 \mathrm{~K}$ Ultrascan 4000 charge-coupled device camera (Gatan Inc.) at a nominal magnification of $\times 9600$, providing a $2 \times$ binned pixel size of $1.94 \mathrm{~nm}$. For tilt series, the specimens were tilted at onedegree intervals using a high-tilt specimen holder (model 2020; E.A. Fischione Instruments, Roskilde, Denmark) between \pm 62 degrees. The Tilt series was aligned and reconstructed with the IMOD software package version 4.7.13, ${ }^{44}$ and the tomographic reconstruction was analyzed, modeled, and visualized with $\mathrm{MIB}^{45}$ software version 0.999 and Amira software version 6.0.1 (FEI).

\section{Immunohistochemistry}

For immunohistochemistry, antigen was retrieved using Tris-EDTA buffer $(\mathrm{pH} 9.0 ; 10 \mathrm{mmol} / \mathrm{L}$ Tris, $1 \mathrm{mmol} / \mathrm{L}$ EDTA, and $0.05 \%$ Tween-20) for 30 minutes in a $95^{\circ} \mathrm{C}$ water bath, after which the sections were allowed to cool down in the buffer. Paraffin-embedded sections of carotid atherosclerotic plaques were stained for apoB-100 (1:100; a mouse monoclonal anti-apoB antibody LS-C35039; Lifespan Biosciences, Seattle, WA, or a polyclonal apoB antibody raised in sheep $1.6 \mu \mathrm{g} / \mathrm{mL}$ of $\mathrm{IgG}$ in antiserum of bleed 20; Sheep L3, THL; Dr. M. Jauhiainen, National Institute for Health and Welfare, Helsinki, Finland), apoE (1:100; clone WU E-4; catalog number sc-53570; Santa Cruz Biotechnology, Dallas, TX), apoA-I (1:5000; clone 1C5; catalog number MON5030; Monosan, Uden, the Netherlands), and apoC-III (1:100; polyclonal rabbit anti-apoC-III; clone H-75; catalog number sc-50377; Santa Cruz Biotechnology). The antibodies were detected using the DAKO EnVision Kit (mouse diaminobenzidine; catalog number K4007; Dako A/S, Glostrup, Denmark), rabbit anti-sheep IgG-horseradish peroxidase (HRP; 1:200; catalog number sc-2770; Santa Cruz Biotechnology), or DAKO EnVision+System HRP (DAB) Rabbit (catalog number K4010; Dako A/S).

\section{Lipoprotein Modification and Generation of Cholesterol Crystals}

LDL $(d=1.019$ to $1.050 \mathrm{~g} / \mathrm{mL})$ and VLDL $(d<1.006 \mathrm{~g} / \mathrm{mL})$ were isolated from plasma donated by healthy volunteers using sequential ultracentrifugation. ${ }^{46}$ The lipoproteins $(1 \mathrm{mg} / \mathrm{mL})$ were modified first by $\mathrm{PLA}_{2}(10 \mathrm{mU} / \mathrm{mL}$; bee venom $\mathrm{PLA}_{2}$; model P9279; Sigma Aldrich, St. Louis, MO), SMase (15 $\mu \mathrm{U} / \mathrm{mL}$; from Bacillus cereus; catalog number S9396; Sigma Aldrich), $\alpha$-chymotrypsin $(4 \mu \mathrm{U} / \mathrm{mL}$; catalog number C4129; Sigma Aldrich), or $5 \mu \mathrm{mol} / \mathrm{L} \mathrm{CuSO}_{4}$ in phosphate-buffered saline containing $2 \mathrm{mmol} / \mathrm{L} \mathrm{CaCl}_{2}$ and $2 \mathrm{mmol} / \mathrm{L} \mathrm{MgCl}_{2}$. After incubation for 18 hours at $37^{\circ} \mathrm{C}$, the reactions were stopped by addition of phenylmethyl sulfonyl fluoride at a final concentration of 0.02 $\mathrm{mg} / \mathrm{mL}$ ( $\alpha$-chymotrypsin) or the addition of EDTA at a final concentration of $10 \mathrm{mmol} / \mathrm{L}$ ( $\mathrm{PLA}_{2}$, SMase, and oxidation). In some cases, the particles were further modified by human recombinant lysosomal acid lipase ${ }^{47}$ (LAL; $6 \mu \mathrm{U} / \mathrm{mL}$ ) in 5 $\mathrm{mmol} / \mathrm{L}$ MES (containing $150 \mathrm{mmol} / \mathrm{L} \mathrm{NaCl} 2 \mathrm{mmol} / \mathrm{L}$ $\mathrm{Ca}^{2+}, 100 \mu \mathrm{mol} / \mathrm{L} \mathrm{Zn}^{2+}$, and $2 \mathrm{mmol} / \mathrm{L} \mathrm{Mg}^{2+}$ ) at a $\mathrm{pH}$ of 5.0 for 24 to 72 hours. ${ }^{47}$ Formation of cholesterol crystals was visualized in light microscopy using a polarizing filter. The cholesterol crystals applied to the cells were generated as follows ${ }^{36}$ : cholesterol was dissolved in $95 \%$ ethanol at a concentration of $12.5 \mathrm{mg} / \mathrm{mL}$ at $60^{\circ} \mathrm{C}$, filtered while warm, and left to crystallize at $20^{\circ} \mathrm{C}$ for 4 to 7 days. Crystals were dried by filtering, ground with a mortar and a pestle in sterile surroundings, and kept at $-20^{\circ} \mathrm{C}$ until used. Endotoxin activity was tested from plasma lipoproteins, isolated extracellular lipoprotein particles, and the dry crystals with an endotoxin kit using a kinetic measuring method (Limulus Amebocyte Lysate Pyrogent Plus; model N294-03; Cambrex, Lonza Group AG, Basel, Switzerland).

\section{Isolation and Analysis of Extracellular Lipoprotein Particles}

Plaque pieces were pooled into sets of 10 to 20 , each piece from an individual plaque, sets weighing on average 2500 $\mathrm{mg}$. Extracellular lipoprotein particles were isolated, as described previously. ${ }^{48}$ Briefly, the snap-frozen tissue was homogenized under liquid nitrogen, and lipoprotein particles were extracted first with buffer containing $0.15 \mathrm{~mol} / \mathrm{L}$ $\mathrm{NaCl}$ and thereafter with buffer containing $1.5 \mathrm{~mol} / \mathrm{L} \mathrm{NaCl}$. The combined extracts were ultracentrifuged for 21 hours in an SW41Ti rotor (Beckman Coulter, Indianapolis, IN; $40,000 \mathrm{rpm}$; gmax $=288,000 \times g$ ) at a density of 1.063 $\mathrm{g} / \mathrm{mL}$, after which the lipoprotein particles were collected from the top of the ultracentrifugation tube. 
The size distribution of the lipoprotein particles was analyzed using rate zonal ultracentrifugation, as described previously. ${ }^{48}$ Oxidized epitopes were determined with a chemiluminescence immunoassay ${ }^{48}$ using mouse monoclonal antibodies recognizing malondialdehyde and malondialdehydeacetaldehyde epitopes. The sizes of the extracellular particles were measured using dynamic light scattering (Zetasizer Nano; Malvern Instruments, Malvern Works, Malvern, UK). The cholesterol and triglyceride contents of the lipoprotein particles were measured by a fluorometric Amplex Red Cholesterol Assay Kit (catalog number A12216; Thermo Fisher Scientific, Waltham, MA) and a triglyceride quantification kit (catalog number K622-100; BioVision, Milpitas, CA), according to the manufacturer's instructions.

\section{Western Blotting}

Isolated extracellular lipoprotein particles, VLDL, LDL, and homogenized plaque tissue (tissue remnants after isolation of the extracellular lipoprotein particles) were homogenized in radioimmunoprecipitation assay buffer using a PowerLyzer 24 Bench Top Bead-Based homogenizer using zirconium oxide beads (MO Bio Laboratories, Carlsbad, CA). They were run in $4 \%$ to $20 \%$ SDS-PAGE gel (165 V, 50 minutes) and transferred onto a polyvinylidene difluoride (Immobilon Psq; MerckMillipore KGaA, Darmstadt, Germany) membrane using wet blot with $20 \%$ methanol in the transfer buffer ( $200 \mathrm{~mA}, 60$ minutes). The antibodies used were a polyclonal antibody against apoB-100 (Dr. M. Jauhiainen) and a respective secondary antibody, rabbit anti-sheep IgG-HRP (1:2000; catalog number 2770; Santa Cruz Biotechnology); a monoclonal antibody against apoE (clone WU E-4; catalog number sc-53570; Santa Cruz Biotechnology) and a respective antibody, goat anti-mouse (catalog number P0447; Dako $\mathrm{A} / \mathrm{S}$; polyclonal goat anti-mouse HRP); and a guinea pig antihuman polyclonal antibody GP29 against perilipin 1 (1:2000; Progen Biotechink GmbH, Heidelberg, Germany) and a respective secondary antibody, an HRP-conjugated rabbit anti-guinea pig (1:10,000; Invitrogen, Camarillo, CA).

\section{Lipid Mass Spectrometry}

The lipids were extracted ${ }^{49}$ from native LDL and isolated extracellular lipoprotein particles, dried under nitrogen flow, and dissolved in chloroform/methanol (1:2). The samples were spiked with a mixture of several quantitative standards, and just before the analysis, $1 \%(\mathrm{v} / \mathrm{v})$ of $\mathrm{NH}_{3}$ was added to each sample to support ionization and prevent adduct formation. The mass spectra, indicating all positive ions, all negative ions, or precursors of the ion $\mathrm{m} / \mathrm{z} 184$ (a specific fragment for the choline head group), were recorded by an Agilent 6490 Triple Quad LC/MS with iFunnel technology (Agilent Technologies, Santa Clara, CA). The data were further analyzed with MassHunter software version B.06.00, November 2012 (Agilent Technologies) and LIMSA (Somerharju Group, University of Helsinki, Helsinki,
Finland) ${ }^{50}$ software version 1.0 (Helsinki, Finland), the latter using the standards and a lipid library.

\section{High-Performance Thin-Layer Chromatography}

Neutral lipid and phospholipid contents were determined using high-performance thin-layer chromatography. Aliquots $(50 \mu \mathrm{L})$ of each lipid sample (in chloroform/ methanol, 1:2) and standards for each lipid class were applied onto silica plates with a CAMAG Automatic TLC Sampler 4 (CAMAG, Muttenz, Switzerland). Standard curves were prepared separately for each lipid class. The lipids of the applied samples were separated onto the plates by using as eluent hexane/diethyl ether/acetic acid/water (26:6:0.4:0.1) for neutral lipids and chloroform/methanol/ acetic acid/water (25:17.5:3.8:1.75) for phospholipids. The plates were developed by dipping them in $3 \% \mathrm{CuSO}_{4} \cdot 5$ $\mathrm{H}_{2} \mathrm{O}+8 \% \mathrm{H}_{3} \mathrm{PO}_{4}$ aqueous solution and heating them on a hot plate until visible sample lines. The lipids were quantified by scanning the plates under UV (254-nm) light by a CAMAG TLC Scanner 3 and integrating the peak areas by the winCATS program (CAMAG version 1.1.3.0).

\section{Circular Dichroism}

Circular dichroism was used to analyze the protein conformation of the extracellular particles. Samples of native LDL or extracellular particles $(50 \mu \mathrm{g} / \mathrm{mL})$ were analyzed by circular dichroism, as described previously, ${ }^{26,51}$ using a JASCO J-715 spectropolarimeter (Japan Spectroscopic Co, Tokyo, Japan). For each sample, five spectra were averaged, and blank measurements were subtracted.

\section{Sample Preparation and Proteolytic Digestion of Proteins for Mass Spectrometry Analysis}

Total protein amounts $(10 \mu \mathrm{g})$ from delipidated samples were digested, using a modified filter-aided sample preparation protocol. ${ }^{52}$ The proteins were reduced, iodoacetamide alkylated, and digested in a 10-kDa cutoff Amicon-0.5 filter (Millipore, Burlington, MA) with lysine-C endopeptidase (Wako, Richmond, VA) in a ratio of $1: 50 \mathrm{w} / \mathrm{w}$ in $4 \mathrm{~mol} / \mathrm{L}$ urea and $0.1 \mathrm{~mol} / \mathrm{L}$ ammonium bicarbonate. The peptide digests were collected by centrifugation, and the digestion was continued using trypsin in a ratio of $1: 50 \mathrm{w} / \mathrm{w}$ in 50 $\mathrm{mmol} / \mathrm{L}$ ammonium bicarbonate at ambient temperature. The peptide digests were collected and combined. The peptides were cleaned using a C18 reverse-phase ZipTip (Millipore), resuspended in 1\% trifluoroacetic acid, and sonicated in a water bath for 1 minute.

\section{Liquid Chromatography-High-Definition Mass Spectrometry}

Digested proteins (300 ng) were injected for liquid chromatography-mass spectrometry analysis. The peptides were 
separated by the nanoAcquity ultraperformance liquid chromatography system (Waters, Manchester, UK), equipped with a $5-\mu \mathrm{m}, 180 \mu \mathrm{m} \times 20 \mathrm{~mm}$ Symmetry C18 reversedphase trapping column (Waters), followed by an analytical $1.7-\mu \mathrm{m}, 75 \mu \mathrm{m} \times 250 \mathrm{~mm}$ BEH-130 C18 reversed-phase column (Waters), in a single-pump trapping mode. The injected sample analytes were trapped at a flow rate of $15 \mu \mathrm{L} /$ minute in $99.5 \%$ of solution A $(0.1 \%$ formic acid). After trapping, the peptides were separated with a linear gradient of $3 \%$ to $35 \%$ of solution B ( $0.1 \%$ formic acid/acetonitrile), for 30 minutes at a flow rate of $0.3 \mu \mathrm{L} /$ minute and a stable column temperature of $35^{\circ} \mathrm{C}$. The samples were run in ion mobility data-independent analysis mode (high-definition mass spectrometry), in a Synapt $\mathrm{G}_{2}-\mathrm{S}$ mass spectrometer (Waters), by alternating between low collision energy $(6 \mathrm{~V})$ and a high collision energy ramp in the transfer compartment (20 to 45 V) and using a 1-second cycle time. The separated peptides were detected online with a mass spectrometer, operated in positive resolution mode in the range of $\mathrm{m} / \mathrm{z} 50$ to $2000 \mathrm{amu}$; $150 \mathrm{fmol} / \mu \mathrm{L}$ of human [Glu1]-fibrinopeptide B (Sigma Aldrich) in 50\% acetonitrile $/ 0.1 \%$ formic acid solution at a flow rate of $0.3 \mu \mathrm{L} /$ minute was used for a lock mass correction, applied every 30 seconds.

\section{Protein Database Search}

ProteinLynx Global Server software version 3.0 (Waters) was used for protein identification. Waters Data Independent analysis MSE parameters were set as follows: lowenergy threshold of 135 counts, elevated energy threshold of 30 counts, and intensity threshold of precursor/fragment ion cluster of 750 counts. Database searches were performed against Homo sapiens UniProtKB-SwissProt, reviewed, database (release 2016_1, 42,145 entries) with an Ion Accounting algorithm and using the following parameters: peptide and fragment tolerance, automatic; maximum protein mass, $750 \mathrm{kDa}$; minimum fragment ion matches per protein, $\geq 7$; minimum fragment ion matches per peptide, $\geq 3$; minimum peptide matches per protein, $\geq 1$; primary digest reagent, trypsin; missed cleavages allowed, 2; fixed modification, carbamidomethylation $\mathrm{C}$; variable modifications, deamidation of NQ amino acid residues, oxidation of methionine, and false-discovery rate of $<4 \%$.

\section{Cell Culture}

Human primary monocytes were isolated from buffy coats obtained from the Finnish Red Cross Blood Service and differentiated into macrophages in the presence of $50 \mathrm{ng} / \mathrm{mL}$ of macrophage-colony-stimulating factor, as previously described. ${ }^{36}$ The cells were used on day 7 of culture. Before activation, the cells were primed with $1 \mu \mathrm{g} / \mathrm{mL}$ lipopolysaccharide (LPS; from Escherichia coli 0111:B4; Sigma Aldrich) for 4 hours. Human primary monocyte-derived macrophages were given native and modified LDL particles (0.3 to $0.4 \mathrm{mg} / \mathrm{mL}$ of protein), in vitro prepared cholesterol crystals $(1 \mathrm{mg} / \mathrm{mL})$, and extracellular lipoprotein particles $(0.3 \mathrm{mg} / \mathrm{mL}$ of protein) isolated from the atherosclerotic lesions. After an overnight incubation, media were collected for IL-1 $\beta$ enzyme-linked immunosorbent assay (ELISA) analysis. Accumulation of cholesteryl esters in the cells was evaluated by thin-layer chromatography. For this purpose, cellular lipids were extracted by incubating phosphatebuffered saline-washed cells with a hexane/isopropanol mixture (3:2). The protein concentrations of the same cells were determined by first disrupting the cells with $0.2 \mathrm{~N}$ $\mathrm{NaOH}$, after which the protein concentration was determined using a bicinchoninic acid protein Assay Reagent Kit (model 232225; Pierce Biotechnology, Rockford, IL).

\section{ELISAs}

IL-1 $\beta$ levels from the cell culture media were measured with ELISA (Human IL-1 $1 /$ IL-1F2 DUOSET ELISA kit; catalog number DY201; R\&D Systems, Oxon, UK), according to the manufacturer's instructions. ApoB-100 was assessed from the extracellular lipoprotein particles using the Human Apolipoprotein B (specific for apoB-100, does not recognize apoB-48) ELISA Development Kit (catalog number 3715-1A-6; Mabtech, Nacka Strand, Sweden).

\section{Statistical Analysis}

Statistical analyses were performed using analysis of variance on ranks with the pair-wise Wilcoxon signed rank test or the nonparametric Kruskal-Wallis test, available in the SPSS statistics software package version 23 (IBM, Armonk, NY). $P<0.05$ was considered statistically significant.

\section{Results}

\section{Electron Microscopic Imaging of Atherosclerotic Lesions}

Pieces of plaques derived from six different endarterectomized carotid atherosclerotic plaques were fixed using a mixture of formaldehyde and glutaraldehyde for maximal preservation of morphology. The fixed samples were further contrasted with four heavy metal staining steps before plastic embedding. In transmission electron microscopy, foam cells, extracellular lipoprotein particles, and cholesterol crystals were observed. Figure 1A shows an example of a foam cell surrounded by extracellular lipoprotein particles and cholesterol crystals (at a higher magnification in Figure 1B). The diameters of the extracellular particles ranged from 50 to $400 \mathrm{~nm}$, whereas intracellular lipid droplets were much larger, with their diameters ranging to $>2000 \mathrm{~nm}$. Supplemental Figure S1A shows a partial cross section of an atherosclerotic lesion starting from endothelial cells and extending $420 \mu \mathrm{m}$ into the intima. The enlargements show a group of large cholesterol crystals in the deep intima (Supplemental Figure S1B), cholesterol crystals 

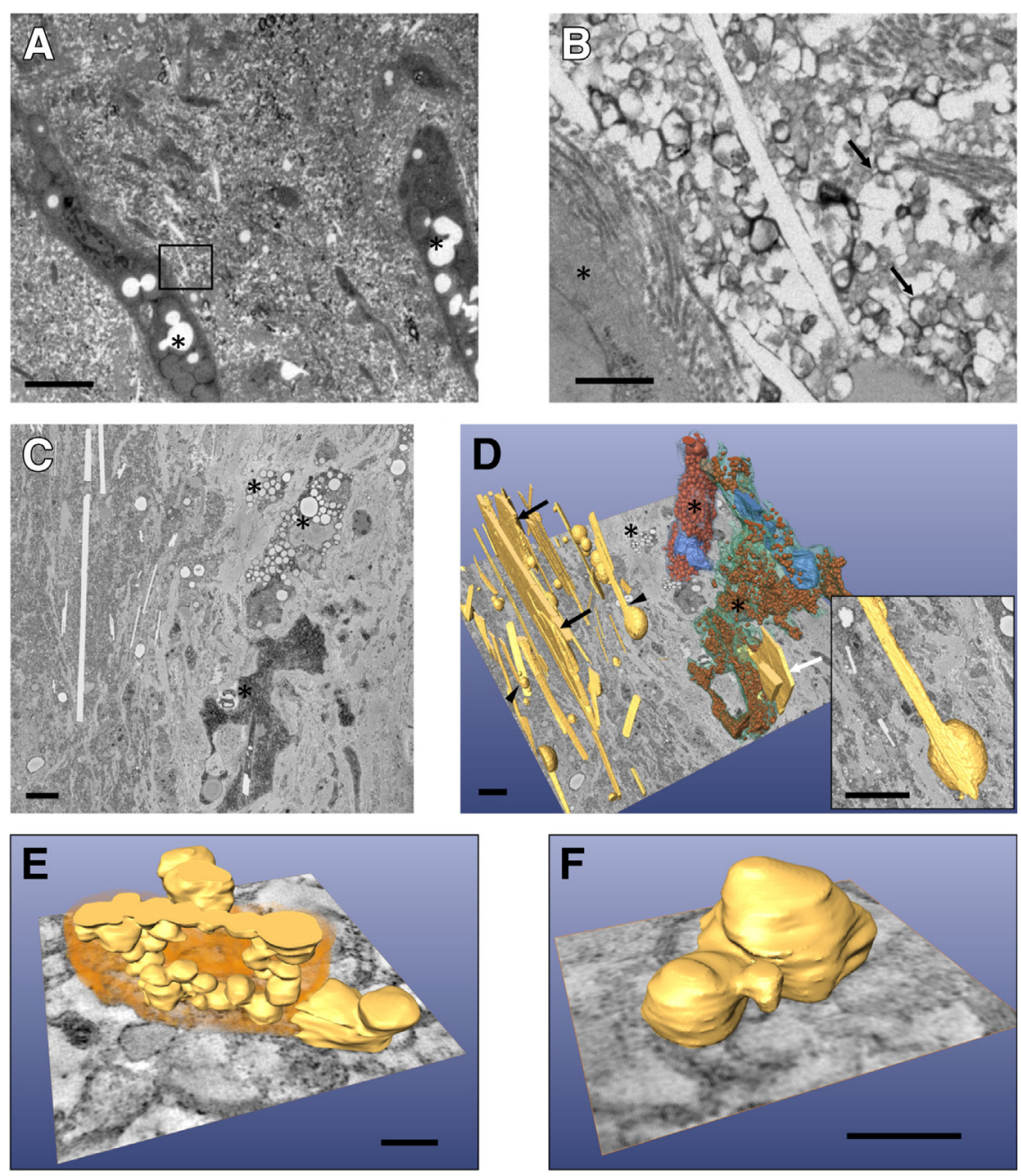

Figure 1 Electron micrographs of an external carotid artery intima containing foam cells, extracellular lipoprotein particles, and cholesterol crystals. A and B: Transmission electron microscopy (TEM) micrograph representative of TEM micrographic analysis of three plaques shows extracellular lipoprotein particles (black arrows in B) and intracellular lipid droplets. B: An enlargement of the boxed area in $\mathbf{A}$. On the basis of TEM analysis, one plaque was selected for block-face scanning electron microscopy (SBEM). C: The lowest block-face image of the SBEM data set. D: Three-dimensional (3D) model of extracellular lipid droplets, cholesterol crystals, and foam cells generated from SBEM images. Cholesterol crystals (yellow) seem to grow out from large lipid droplets (black arrowheads and inset). Large sheet-like crystals (black arrows) can be two dimensionally as large as foam cells. The plasma membranes of the foam cells are artificially colored in transparent blue or green, the nuclei in light blue, and the intracellular lipid droplets in vermilion or maroon. Two cholesterol crystals are surrounded by the right-hand foam cell (white arrow). A-D: Foam cells are marked with asterisks. E and F: 3D models generated from tomographic reconstruction of the plaque used for SBEM depict extracellular lipoprotein particles in a process of fusion. Scale bars: $5 \mu \mathrm{m}(\mathbf{A}, \mathbf{C}$, and D); $0.5 \mu \mathrm{m}(\mathbf{B}) ; 0.1 \mu \mathrm{m}$ ( $\mathbf{E}$ and $\mathbf{F})$. inside and next to foam cells (Supplemental Figure S1, $\mathrm{C}$ and D), and small cholesterol crystals $(<0.5 \mu \mathrm{m})$ among extracellular lipoprotein particles (Supplemental Figure S1, E and F).

A specimen of an atherosclerotic carotid plaque was selected for SBEM, in which 340 block faces, each $40 \mathrm{~nm}$ apart, were sequentially cut and imaged. The resulting volume was aligned and segmented to generate a 3D model of organization of cholesterol crystals and foam cells (Supplemental Video S1). A representative block-face image is shown in Figure 1C. The micrographs acquired by SBEM revealed 3D cholesterol crystals embedded in lipoprotein particle-containing extracellular matrix. The 3D model generated from the SBEM data set is shown in Figure 1D and in Supplemental Videos S1 and S2. The needle-like crystals appeared to grow out of exceptionally large extracellular lipoprotein particles, and some crystals appeared as large sheet-like structures (Figure 1D). One of the foam cells appeared to be in the process of engulfing two cholesterol crystal sheets (Figure 1D and Supplemental Video S2). To obtain the 3D organization of the extracellular lipoprotein particles at higher resolution, electron tomography of the same plaque specimen was also performed, which allowed various projection images of a semithick section to be collected and reconstructed into a 3D tomographic volume. Using this method, aggregated lipoprotein particles, some of which appeared to be fusing (Figure 1, E and F, and Supplemental Video S3), were observed. The diameters of these extracellular particles ranged from 15 to $135 \mathrm{~nm}$, indicating that some of the particles are smaller than plasma LDL (20 to $25 \mathrm{~nm}$ ), whereas some were much larger.

\section{Generation of Cholesterol Crystals in Vitro}

Hydrolysis of LDL with the combination of SMase and cholesteryl esterase produces cholesterol crystals in vitro. ${ }^{30}$ This observation and our present electron microscopic demonstration of cholesterol crystals appearing to grow out from extracellular lipoprotein particles prompted us to test whether other modifications of plasma LDL, such as lipolysis with $\mathrm{PLA}_{2}$, oxidation, or proteolysis, in combination with cholesteryl ester hydrolysis would be able to induce the formation of cholesterol crystals. Cholesterol is known to 
A

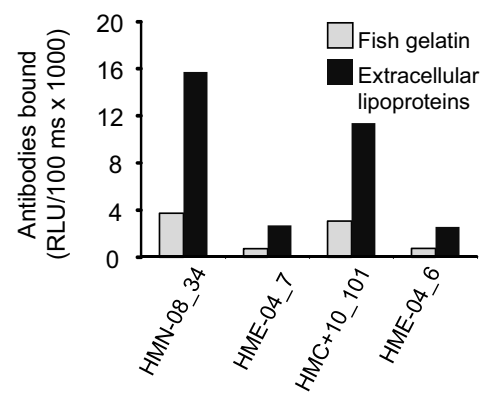

D

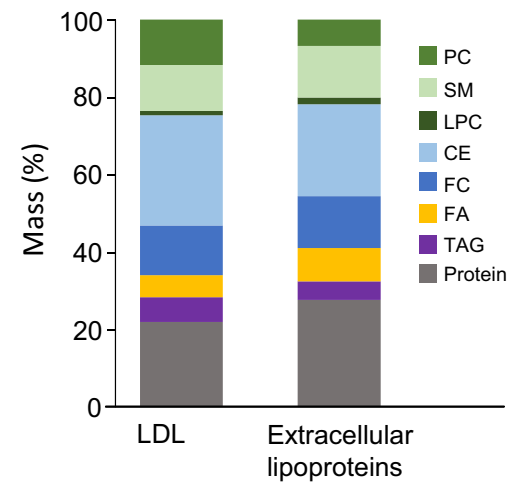

B

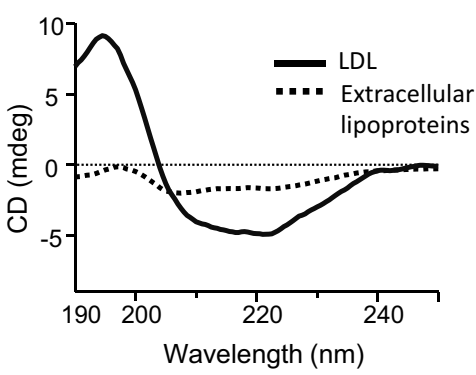

C

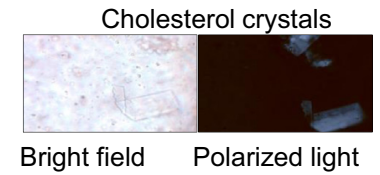

Figure 2 Characterization of the extracellular lipoprotein particles. A: Binding of four different monoclonal antibodies generated against malonaldehyde-low-density lipoprotein (LDL) or malondialdehyde-acetaldehyde-LDL to a single extracellular lipoprotein particle preparation. Fish gelatin was used as a negative control. The results are expressed as relative light units (RLUs) measured in 100 milliseconds. B: Circular dichroism analysis of LDL and extracellular lipoprotein particles. Representative spectrum of extracellular lipoprotein particles isolated from a pool of 10 pieces derived from 10 individual plaques. Similar results were obtained with another preparation of extracellular lipoprotein particles prepared from a pool of 10 plaque pieces derived from another 10 individual plaques. The samples were diluted to give a protein concentration of $50 \mu \mathrm{g} / \mathrm{mL}$, and far-UV circular dichroism spectra were recorded using a 0.1-cm quartz cuvette in the region of 190 to $250 \mathrm{~nm}$. Solid line, LDL; dashed line, extracellular lipoproteins; dotted line, zero level in circular dichroism signal (CD) (mdeg). C: The presence of cholesterol crystals in the extracellular lipoprotein particle preparations was analyzed under polarized light. D: Lipid contents of the LDL and extracellular lipoprotein particles were determined by thin-layer chromatography and are shown as mass percentages of the total mass (lipids + protein). Averages of three preparations are shown. CE, cholesteryl ester; FA, fatty acid; FC, free cholesterol; LPC, lysophosphatidylcholine; PC, phosphatidylcholine; SM, sphingomyelin; TAG, triacylglycerol.

crystallize when a critical concentration of unesterified cholesterol has been achieved. ${ }^{53}$ We hypothesized that cholesterol crystallization would occur when CEs in the LDL core are hydrolyzed into unesterified cholesterol. Because destabilization of the LDL surface significantly improves CE hydrolysis, ${ }^{13}$ LDL particles were first treated

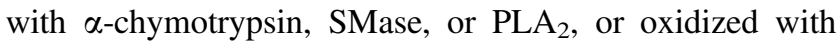
copper sulfate to destabilize the particle surface. Thereafter, the particles were treated with LAL to hydrolyze the CEs in the LDL core. Examination of the modified LDL particles under polarized light showed that each of these modifications and even treatment of LDL with LAL without any prior modification were able to induce the formation of cholesterol crystals (Supplemental Figure S2).

\section{Characterization of the Extracellular Lipoprotein Particles}

Immunohistochemistry of carotid artery plaques showed the presence of apoB, apoE, apoA-I, and apoC-III, reflecting entry LDL and other plasma lipoproteins into the plaques (Supplemental Figure S3). To gain information on the origins and effects of the lipoprotein-derived lipid particles, extracellular particles from plaques were next isolated and analyzed using a method optimized for this purpose.$^{48}$ Pieces of 10 to 20 individual plaques were pooled for each lipoprotein particle isolation. The isolated extracellular lipoprotein particles were found to contain apoB-100, as demonstrated when analyzing them by chemiluminescent immunoassay (Supplemental Figure S4A) or Western blotting (Supplemental Figure S4B). In addition, apoE was detected in the extracellular lipoprotein particles by Western blotting (Supplemental Figure S4B). A more detailed proteomic analysis of extracellular lipoprotein particles by mass spectrometry confirmed the presence of apoB-100 and apoE. It also indicated the presence of other apolipoproteins, such as apoA-I and apoC-III, complement components $\mathrm{C} 3$ and $\mathrm{C} 9$, and immunoglobulins $\operatorname{IgG}$, IgM, and IgA (Supplemental Table S1). Markers of intracellular lipid droplets, such as perilipin, were not detected in the isolated particles; while in the homogenized tissue, perilipin was abundant (Supplemental Figure S4C).

The extracellular lipoprotein particles contained epitopes recognized by antibodies generated against malondialdehydeLDL and malondialdehyde acetaldehyde-LDL, indicating their oxidative modification (Figure 2A). Circular dichroism analysis indicated that the conformation of the proteins in the isolated extracellular lipoprotein particles differed from that in LDL particles and that their $\alpha$-helical content was much lower than that in plasma LDL (Figure 2B). The extracellular lipoprotein preparations were found to contain cholesterol crystals (Figure 2C). The proportions of phosphatidylcholines (PCs) and CEs were lower, and the proportion of free fatty acids was higher, than in LDL particles (Figure 2D), suggesting that the extracellular lipoproteins had also undergone lipolysis. The higher proportion of protein in the particles compared with plasma LDL points to the same but may also be indicative of the 
A

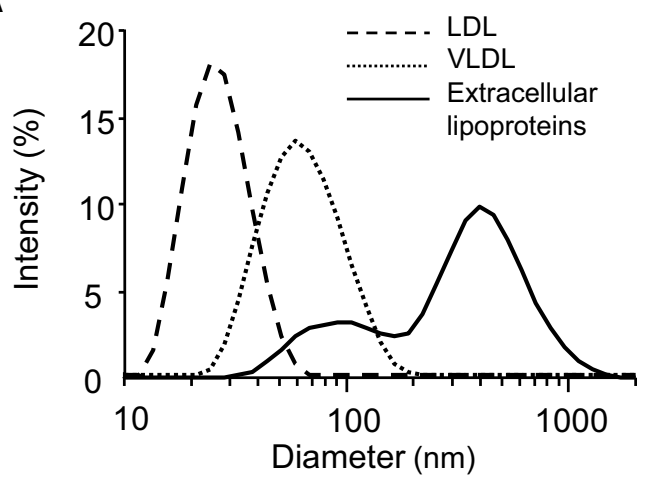

B

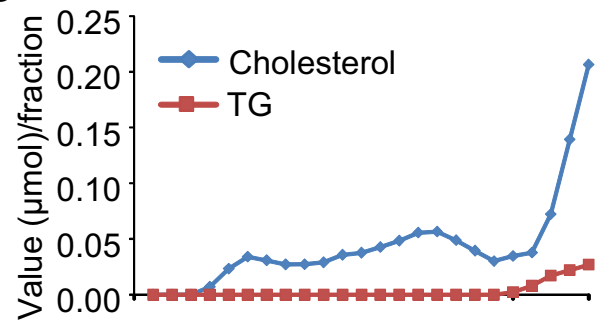

C

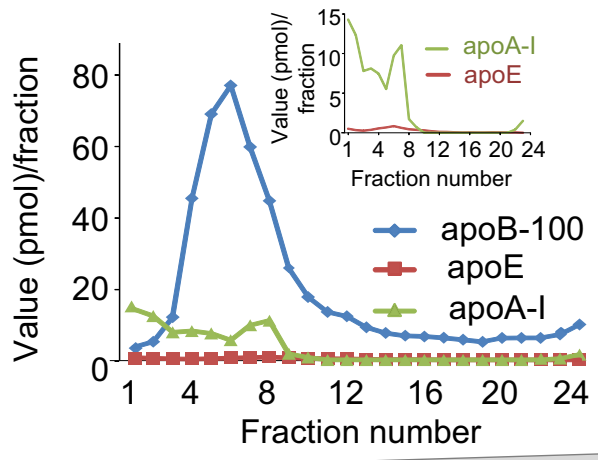

Particle size

Figure 3 Size and fractionation of extracellular lipoproteins. A: Sizes of low-density lipoprotein (LDL), very-low-density lipoprotein (VLDL), and extracellular lipoprotein particles were measured with dynamic light scattering. The data are representative of three individual preparations. B and C: The extracellular lipoproteins were fractionated on the basis of particle size using rate zonal ultracentrifugation, and the amounts of total cholesterol and triglycerides (B) and apolipoprotein (apo) B-100, apoA-I, and apoE (C) in each fraction were determined. Three lipoprotein particle preparations, each from a pool of 10 to 20 pieces of individual plaques, were analyzed by rate zonal ultracentrifugation. The cholesterol and apoB-100 contents were analyzed in each of these preparations. Triglycerides (TGs), apoA-I, and apoE were analyzed from one preparation of 10 pooled plaques.

extracellular lipoprotein particles containing several different proteins, as described in the preceding paragraph. The low PC content of the particles was reflected in a decrease in the proportion of a major PC species 34:2 (Supplemental Figure S5A). Changes in the lysophosphatidylcholine and sphingomyelin species were more subtle (Supplemental Figure S5, B and C). The CE composition of the extracellular lipoprotein particles differed from that of plasma LDL. Thus, although the proportion of CE 18:2, the most common in LDL, was dramatically lower in the extracellular lipoprotein particles, they had a high but varying proportion of CE 18:3 (Supplemental Figure S6).

Dynamic light scattering analysis revealed that the isolated extracellular lipoprotein particles were much larger (40 to 1000 $\mathrm{nm}$ ) than plasma LDL (average diameter, $24 \mathrm{~nm}$ ) or VLDL (average diameter, $58 \mathrm{~nm}$ ) (Figure 3A). The extracellular lipoproteins had a wide size distribution when analyzed using rate zonal ultracentrifugation (Figure 3, B and C). Cholesterol was distributed among the small and large particles, whereas triglyceride was found only in the largest particles (Figure 3B). ApoE and apoA-I were found only in the small particles, and their molar concentrations were much lower than that of apoB100. Immunoreactive apoB-100 was found mainly in the small particles. In this assay, an antibody against a $\mathrm{C}$-terminal epitope is used. Because this epitope is not present in apoB-48, the finding suggests the larger particles may be derived from apoB-48-containing particles or that apoB-100 in the large particles had been partially lost or modified (Figure 3C).

\section{Proinflammatory Activity of Isolated Extracellular Lipoprotein Particles}

Cholesterol crystals are a known activator of the NLRP3 inflammasome, an inflammatory pathway that leads to activation of caspase- 1 and to secretion of caspase- $1-$ activated IL- $1 \beta$ and IL-18. ${ }^{35,36}$ To study whether the isolated extracellular lipoprotein particles are able to induce inflammasome activation, monocyte-derived macrophages were incubated with or without $1 \mu \mathrm{g} / \mathrm{mL}$ of LPS. Afterwards, the cells were further incubated in the presence of the lipoprotein particle preparations or, as a positive control, in vitro-generated cholesterol crystals. In the primary human monocyte-derived macrophages, LPS induces transcription of $N L R P 3$ and $I L I B$, and thereby serves as a necessary priming signal for inflammasome activation and IL$1 \beta$ secretion. ${ }^{54}$ The lipoprotein particle preparations and cholesterol crystals induced secretion of IL-1 $\beta$ in LPS-primed, but not in non-primed, human macrophages (Figure 4A). In the non-primed macrophages, the lipoprotein particle preparations, similar to in vitro-generated cholesterol crystals, ${ }^{36}$ did not induce significant expression of $N L R P 3$ or TNFA, nor did they induce expression of $M C P 1$ (data not shown).

To test whether modified lipoproteins were able to induce IL- $1 \beta$ secretion and activation of inflammasome complexes, similar to the isolated lipoprotein particle preparations, LDL surface phospholipids and proteins were first modified using proteolysis, lipolysis, or oxidation of the particles, after which the core CEs were hydrolyzed by LAL. All these modifications induced formation of cholesterol crystals (Supplemental Figure S2). LDL hydrolyzed with a combination of $\mathrm{PLA}_{2}$ and LAL induced a robust IL-1 $\beta$ secretion (Figure 4B). Unexpectedly, neither oxidized LDL nor oxidized LDL treated with LAL was able to induce IL-1 $\beta$ secretion by the human macrophages. Similar to LDL modified with $\mathrm{PLA}_{2}$ and LAL, VLDL modified by the same enzymes induced secretion of IL-1 $\beta$ (Figure $4 \mathrm{C}$ ). Secretion of IL- $1 \beta$ could be inhibited by a caspase- 1 inhibitor, thereby 


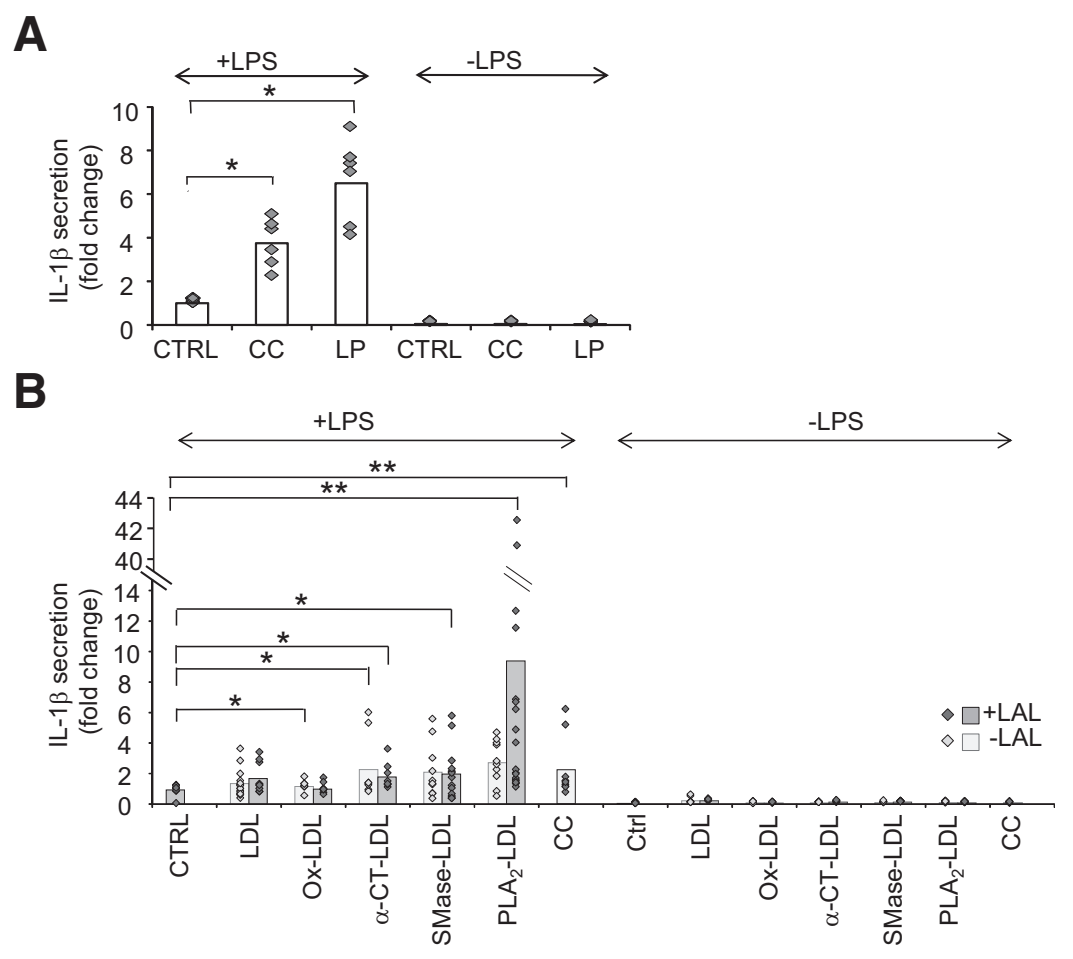

C
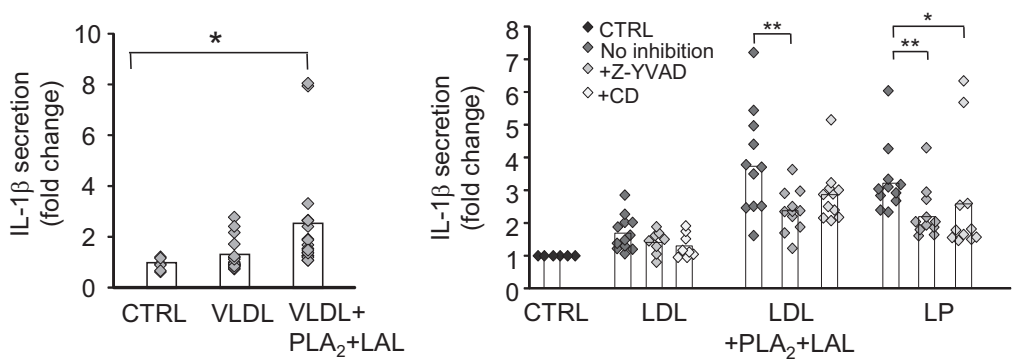

Figure 4 Inflammasome activation in human monocyte-derived macrophages. A: Monocyte-derived macrophages were primed with or without lipopolysaccharide (LPS) for 4 hours, after which extracellular lipoprotein particles or in vitro-generated cholesterol crystals were incubated with the cells for 18 hours. The concentration of IL- $1 \beta$ was measured in cell culture supernatants. B: Low-density lipoprotein (LDL) was modified by oxidation, proteolysis, or phospholipolysis either alone or in combination with lysosomal acid lipase (LAL)-induced cholesteryl ester hydrolysis for 18 hours. Native or modified LDL was then incubated with LPS-primed or non-primed human monocyte-derived macrophages for 18 hours, after which the concentration of IL- $1 \beta$ was determined in the supernatants. C: LPS-primed human monocyte-derived macrophages were incubated with verylow-density lipoprotein (VLDL) or VLDL modified with phospholipase $A_{2}\left(P L A_{2}\right)$ and LAL for 18 hours. After the incubation, the concentrations of IL-1 $\beta$ were determined from the supernatants. D: LPS-primed human monocytederived macrophages were incubated with LDL, LDL modified with $\mathrm{PLA}_{2}$ and $\mathrm{LAL}$, or extracellular lipoprotein particles in the absence or presence of caspase- 1 inhibitor Z-YVADfmk (Z-YVAD) or cytochalasin D (CD), an inhibitor of cytoskeletal movements. Each data point is shown as a diamond, and averages are shown as columns. $n=6(\mathrm{~A})$; $n=6$ to 12 (B); $n=6$ to 18 (C); $n=10$ to 12 (D). ${ }^{*} P<0.05,{ }^{* *} P<0.005 . \alpha$-CT, $\alpha$-chymotrypsin; CC, cholesterol crystal; CTRL, control; LP, extracellular lipoprotein particle; $0 x-L D L$, copper-oxidized LDL; SMase, sphingomyelinase. confirming that it was inflammasome dependent (Figure 4D). Also, inhibition of uptake of the extracellular lipoprotein particles or modified LDL with cytochalasin D partly inhibited IL-1 $\beta$ secretion (Figure 4D). The isolated extracellular lipoproteins, VLDL (both native and lipolyzed with $\mathrm{PLA}_{2}$ and LAL), LDL lipolyzed with $\mathrm{PLA}_{2}$ and LAL, and cholesterol crystals all were able to induce $\mathrm{CE}$ accumulation in the cells, but there were marked compositional differences between the differently treated cells (Figure 5). Thus, cholesterol crystals and modified LDL induced accumulation of CEs, whereas the extracellular lipoprotein particles and native and lipolyzed VLDL induced the accumulation of triacylglycerols. Cholesterol crystals also induced the accumulation of unesterified cholesterol.

\section{Discussion}

To understand the origin of lipid accumulating in atherosclerotic plaques and their pathophysiological significance in human atherogenesis, we assessed the ultrastructure, chemical composition, and proinflammatory potential of lipoprotein particles isolated from endarterectomized carotid artery plaques. We demonstrate that the extracellular lipoprotein particles are derived from modified apoB-containing plasma lipoproteins. When these particles were added to cultured human monocyte-derived macrophages, they triggered proinflammatory activation of macrophages and induced lipid accumulation in the cells in vitro. 3D-EM of the plaques revealed areas where the extracellularly located lipoprotein particles, foam cells, and cholesterol crystals were colocalized.

ApoB-100 was found to be the main protein component of the isolated extracellular lipoprotein particles, indicating that the particles were derived from the atherogenic class of plasma lipoproteins containing this apolipoprotein. In addition, chylomicron remnants, another likely source of plasma-derived plaque lipids, also contribute to the accumulating extracellular lipids in the carotid plaques. Mass 


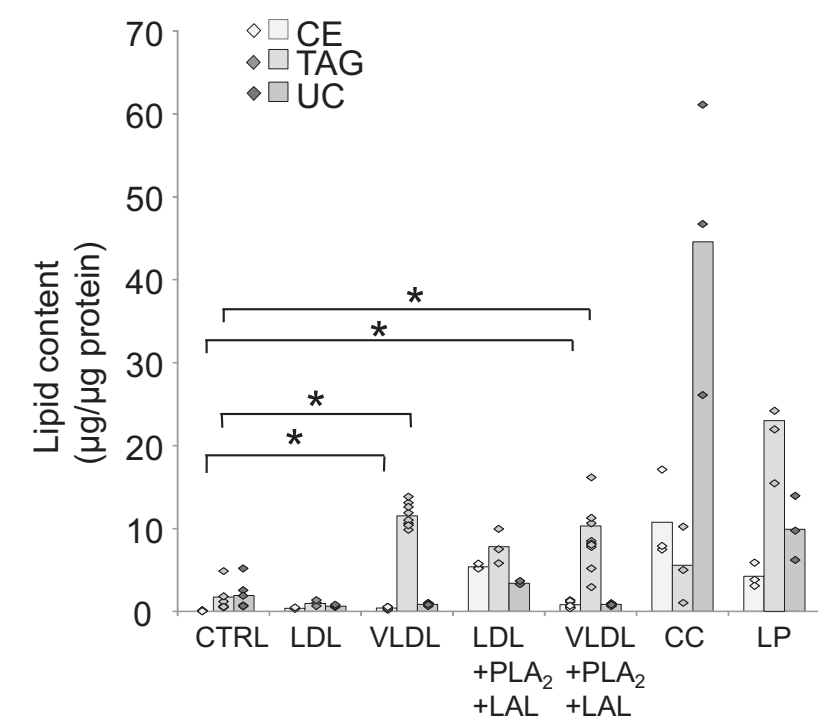

Figure 5 Lipid accumulation in human monocyte-derived macrophages. Low-density lipoprotein (LDL), very low density lipoprotein (VLDL), enzymatically modified LDL [LDL+phospholipase $A_{2}\left(P L A_{2}\right)+$ lysosomal acid lipase (LAL)], enzymatically modified VLDL (VLDL+PLA $\left.{ }_{2}+\mathrm{LAL}\right)$, in vitro-generated cholesterol crystals (CCS), and extracellular lipoproteins (LPs) were applied to human primary monocyte-derived macrophages. After incubation for 18 hours, the cellular lipid contents were analyzed by thin-layer chromatography. $n=3$ to 9 . Averages of the individual data points are shown as columns. ${ }^{*} P<0.05$. CE, cholesteryl ester; CTRL, control; TAG, triacylglycerol; UC, unesterified cholesterol.

spectrometric analysis of the particle proteins confirmed the presence of several small exchangeable apolipoproteins, including apoE, apoA-I, apoC-I, and C-III, which are known to be present in all major lipoprotein classes. ${ }^{55,56}$ The extracellular lipoprotein particles contained complement components, which have been detected in plasma highdensity lipoprotein particles. ${ }^{57}$ Moreover, immunoglobulins were found to be associated with the extracellular lipoprotein particles, a finding suggesting local formation of immunocomplexes, such as those that have been reported for oxidized LDL in human atherosclerotic lesions. ${ }^{58}$ The isolated particles did not contain markers of intracellular lipid droplets, such as perilipin. The apolipoprotein composition of the extracellular lipoproteins suggests that they are derived from multiple classes of plasma lipoproteins, from chylomicron remnants to high-density lipoprotein particles. Because apoE is secreted by macrophages, ${ }^{59}$ it is also possible that this protein as well as complement components and immunoglobulins are incorporated into the extracellular lipoproteins in the tissue.

Circular dichroism analysis indicated that the protein components of the isolated lipoprotein particles had largely lost their secondary structure. This may have resulted from degradation of the protein components or from lipolytic modifications because lipolytic modifications of plasma lipoproteins have been reported to compromise the conformation of their apolipoproteins. ${ }^{26,60}$ Indeed, when compared with native LDL particles, the lipid composition of the isolated lipoprotein particles suggested that they had been exposed to the action of both phospholipases and cholesteryl esterases. Their low CE and PC content and decreased PC/ sphingomyelin ratio are in accordance with previously published results. ${ }^{12,61,62}$ Compared with the PC species profile of LDL, the lipoprotein particles were enriched with oxidationresistant saturated and monounsaturated species, and with arachidonic acid-containing species with a proinflammatory potential (eg, PC 38:4 acyl pair 18:0/20:4n-6).

The lipoprotein particle preparations were also found to contain cholesterol crystals. More important, hydrolysis of CEs in the core of plasma lipoprotein particles can induce formation of cholesterol crystals, as previously shown by Guarino and coworkers, ${ }^{30}$ by producing cholesterol crystals by hydrolysis of LDL with SMase and cholesteryl esterase. Herein, we show that modification of the surface of LDL particles by proteolysis, phospholipolysis, or oxidation facilitates effective CE hydrolysis, leading to induction of cholesterol crystal formation. These modifications have also been shown to induce aggregation and fusion of plasma LDL particles, ${ }^{8}$ findings compatible with our present electron microscopic observations of aggregated and fused lipoprotein particles in carotid atherosclerotic plaques.

Various electron microscopic techniques (scanning electron microscopy and transmission electron microscopy) have been previously used to image foam cells and extracellular lipoprotein particles in atherosclerotic plaques derived from animals ${ }^{63-65}$ or humans. ${ }^{66-68}$ Interestingly, freeze fracturing combined with scanning electron microscopy has provided images of the lipid particles and of their lamellar structure. ${ }^{65,69}$ In this study, we used two complementary EM techniques: electron tomography, which allowed us to detect individual lipoprotein particles, even in their fusion process; and SBEM, which allowed observation of cholesterol crystals, extracellular lipoprotein particles, and foam cells within an atherosclerotic plaque. These techniques made it possible to examine the 3D structure of the plaque microdomains and, thus, to uncover novel information of the positioning and nature of the extracellular lipoprotein particles and cholesterol crystals in the intima. Models generated from the SBEM data set revealed sheetlike cholesterol crystals that were as large as the neighboring foam cells and needle-like crystals that were connected to extracellular particles and seemingly growing out of them. Such large sheet-like crystals have not been observed in atherosclerotic plaques with any other EM technique. The sheet-like crystals represent likely late-stage forms of the cholesterol crystallization process, which, as shown in bile, evolves from needle-like structures. ${ }^{70}$

Interestingly, in the model generated from the SBEM data set, one of the plaque foam cells appeared to be in the process of phagocytosing cholesterol crystals. Uptake of cholesterol crystals by cultured macrophages has been found to activate the NLRP3 inflammasome in them. ${ }^{35,36}$ Inflammasome activation is a two-step process, in which the first step, the priming, is induced (eg, by LPS $)^{71}$ and leads to induction of transcription of $N L R P 3, C A S P 1$, and 


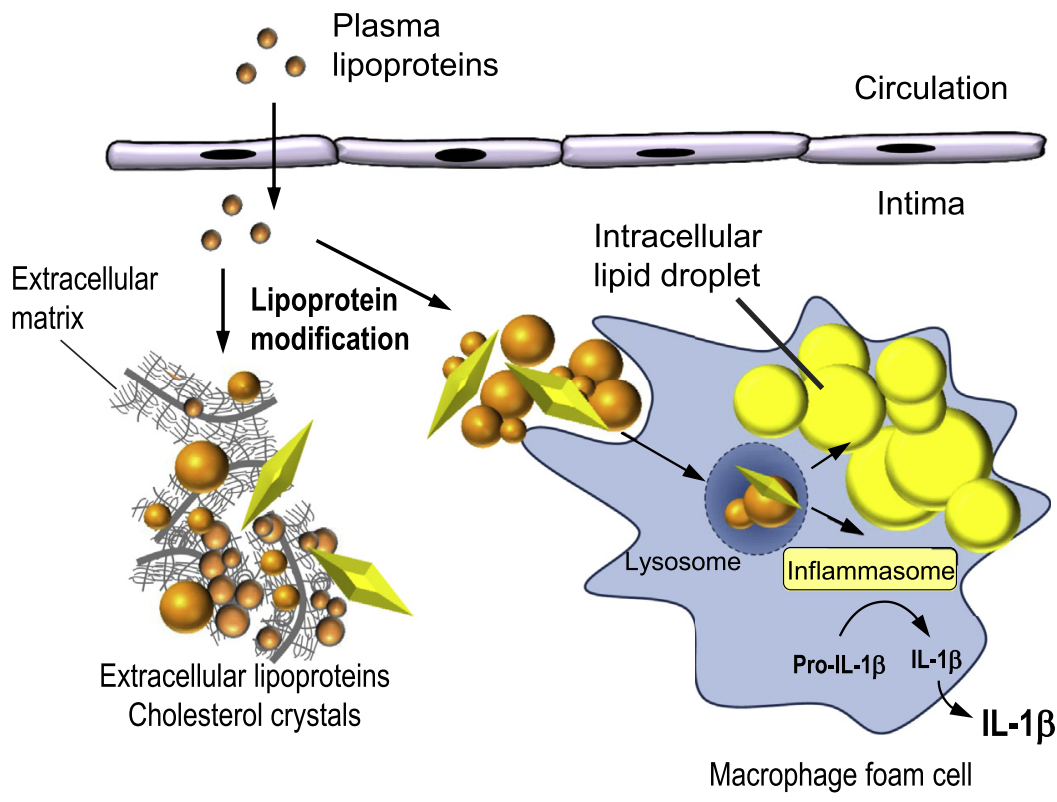

Figure 6 Proposed role of extracellular lipoprotein particles in atherogenesis. Extracellular lipoprotein particles are derived from plasma apolipoprotein Bcontaining lipoproteins by modification and aggregation. Such modifications can also induce formation of cholesterol crystals. The extracellular lipoprotein particles, together with cholesterol crystals, induce extracellular lipid accumulation. The extracellular lipoproteins and cholesterol crystals can also be taken up by macrophages, thereby inducing foam cell formation and inflammasome activation, with ensuing IL-1 $\beta$ secretion.
$I L I B$ (ie, to the generation of the machinery required for secretion of mature IL-1 $\beta$ ). A potential source of LPS in atherosclerotic lesions is oral pathogens. ${ }^{72}$ Other priming components include components of the extracellular matrix, such as biglycan, that can interact with toll-like receptors. ${ }^{73}$ In the second step, assembly and activation of the inflammasome complex are triggered by inflammasome activators, such as cholesterol crystals. In this study, we show that the plaque-derived lipoprotein particles are able to trigger inflammasome activation in LPS-primed macrophages. Cytochalasin D induced a partial reduction in the secretion of IL-1 $\beta$, indicating that the process was at least partly dependent on the internalization of the lipoprotein particles. The lipoprotein particle preparations contained cholesterol crystals, rendering it possible that the observed inflammasome activation in the cultured human macrophages was caused solely by them. However, of all types of LDL modifications that induced the formation of cholesterol crystals, only those involving hydrolysis of both PCs and CEs were able to trigger robust IL- $1 \beta$ secretion in cultured human macrophages.

This study demonstrates that the aggregated and fused extracellular lipoprotein particles present in human atherosclerotic lesions are derived mainly from apoB-containing plasma lipoproteins and that they have undergone modifications able to induce lipoprotein aggregation and formation of cholesterol crystals (Figure 6). The extracellular lipoprotein particle preparations induced inflammasome activation and, therefore, the particles can be considered active inflammatory contributors in atherogenesis. Considering that IL-1 $\beta$, a product of inflammasome activation, is able to induce secretion of matrix metalloproteinase-1, an enzyme with collagenase activity, ${ }^{74,75}$ lipoprotein particle-induced inflammasome activation may also lead to weakening and rupture of an atherosclerotic plaque and contribute to the development of atherothrombotic complications. Moreover, because inflammasome activation has been shown to induce cell death by apoptosis and pyroptosis, ${ }^{76}$ uptake of extracellular lipoprotein particles may also contribute to death of intimal cells and, like cholesterol crystals, associate with plaque vulnerability. ${ }^{77}$ Thus, plasma lipoproteins retained and modified in the arterial intima can induce both lipid accumulation and inflammation, two key processes that are involved in the formation and progression of atherosclerosis. Finally, multidimensional imaging of the extracellular lipoprotein particles in their genuine environment (ie, in a human atherosclerotic plaque) allows us to better define the ultrastructural architecture of human atherosclerotic lesions and aids in understanding of the detailed structure-function relationships of the lipid components in atherogenesis.

\section{Limitations of the Study}

The method used for isolation of the extracellular lipoprotein particles is a compromise in that the homogenization needs to be sensitive enough to avoid breaking of the foam cells, with ensuing release of their intracellular lipid droplets, or causing artificial aggregation of the extracellular particles. Yet, the homogenization needs to be efficient enough to be able to liberate lipid particles as much as possible. Because we did not observe markers of intracellular lipid droplets in the proteomic analysis of the isolated particles, the presence of at least sizeable amounts of lipid droplets of intracellular origin among extracellular particles seems highly unlikely. Intracellular lipid droplets would also have been detected by their large size in the dynamic light scattering analysis and the rate zonal ultracentrifugation. ${ }^{48}$ Heavy water-based ultracentrifugation was chosen 
during the isolation procedure, which is known to minimize the loss of small exchangeable apolipoproteins during the ultracentrifugation step. ${ }^{55}$ Also, apoB-100 immunoaffinity columns were not selected to avoid examining only apolipoprotein prespecified particles (eg, only apoB$100-$ containing particles).

\section{Acknowledgments}

We thank Maija Atuegwu, Sirpa Rannikko, Sonja Kasari, Jaana Kautto, Sanna Sihvo, Antti Salminen, and Mervi Lindman for excellent technical assistance.

\section{Supplemental Data}

Supplemental material for this article can be found at https://doi.org/10.1016/j.ajpath.2017.09.019.

\section{References}

1. Grotta JC: Carotid stenosis. N Engl J Med 2013, 369:2360-2361

2. Nielsen LB, Gronholdt ML, Schroeder TV, Stender S, Nordestgaard BG: In vivo transfer of lipoprotein(a) into human atherosclerotic carotid arterial intima. Arterioscler Thromb Vasc Biol 1997, 17:905-911

3. Nielsen LB: Transfer of low density lipoprotein into the arterial wall and risk of atherosclerosis. Atherosclerosis 1996, 123:1-15

4. Chapman MJ, Ginsberg HN, Amarenco P, Andreotti F, Boren J, Catapano AL, Descamps OS, Fisher E, Kovanen PT, Kuivenhoven JA, Lesnik P, Masana L, Nordestgaard BG, Ray KK, Reiner Z, Taskinen MR, Tokgozoglu L, Tybjaerg-Hansen A, Watts GF: Triglyceride-rich lipoproteins and high-density lipoprotein cholesterol in patients at high risk of cardiovascular disease: evidence and guidance for management. Eur Heart J 2011, 32:1345-1361

5. Boren J, Olin K, Lee I, Chait A, Wight TN, Innerarity TL: Identification of the principal proteoglycan-binding site in LDL: a singlepoint mutation in apo-B100 severely affects proteoglycan interaction without affecting LDL receptor binding. J Clin Invest 1998, 101:2658-2664

6. Camejo G, Olsson U, Hurt-Camejo E, Baharamian N, Bondjers G: The extracellular matrix on atherogenesis and diabetes-associated vascular disease. Atheroscler Suppl 2002, 3:3-9

7. O’Brien KD, Olin KL, Alpers CE, Chiu W, Ferguson M, Hudkins K, Wight TN, Chait A: Comparison of apolipoprotein and proteoglycan deposits in human coronary atherosclerotic plaques: colocalization of biglycan with apolipoproteins. Circulation 1998, 98:519-527

8. Öörni K, Pentikäinen MO, Ala-Korpela M, Kovanen PT: Aggregation, fusion, and vesicle formation of modified low density lipoprotein particles: molecular mechanisms and effects on matrix interactions. J Lipid Res 2000, 41:1703-1714

9. Hoff HF, Gaubatz JW: Isolation, purification, and characterization of a lipoprotein containing Apo B from the human aorta. Atherosclerosis 1982, 42:273-297

10. Ylä-Herttuala S, Palinski W, Rosenfeld ME, Steinberg D, Witztum JL: Lipoproteins in normal and atherosclerotic aorta. Eur Heart J 1990, 11 Suppl E:88-99

11. Smith EB, Evans PH, Downham MD: Lipid in the aortic intima: the correlation of morphological and chemical characteristics. J Atheroscler Res 1967, 7:171-186

12. Smith EB, Slater RS, Chu PK: The lipids in raised fatty and fibrous lesions in human aorta: a comparison of the changes at different stages of development. J Atheroscler Res 1968, 8:399-419
13. Hakala JK, Oksjoki R, Laine P, Du H, Grabowski GA, Kovanen PT, Pentikäinen MO: Lysosomal enzymes are released from cultured human macrophages, hydrolyze LDL in vitro, and are present extracellularly in human atherosclerotic lesions. Arterioscler Thromb Vasc Biol 2003, 23:1430-1436

14. Plihtari R, Hurt-Camejo E, Öörni K, Kovanen PT: Proteolysis sensitizes LDL particles to phospholipolysis by secretory phospholipase A2 group V and secretory sphingomyelinase. J Lipid Res 2010, 51: 1801-1809

15. Wang J, Sjoberg S, Tang TT, Öörni K, Wu W, Liu C, Secco B, Tia V, Sukhova GK, Fernandes C, Lesner A, Kovanen PT, Libby P, Cheng X, Shi GP: Cathepsin G activity lowers plasma LDL and reduces atherosclerosis. Biochim Biophys Acta 2014, 1842:2174-2183

16. Öörni K, Sneck M, Brömme D, Pentikäinen MO, Lindstedt KA, Mäyranpää M, Aitio H, Kovanen PT: Cysteine protease cathepsin F is expressed in human atherosclerotic lesions, is secreted by cultured macrophages, and modifies low density lipoprotein particles in vitro. J Biol Chem 2004, 279:34776-34784

17. Edelstein C, Nakajima K, Pfaffinger D, Scanu AM: Oxidative events cause degradation of apoB-100 but not of apo[a] and facilitate enzymatic cleavage of both proteins. J Lipid Res 2001, 42: $1664-1670$

18. Kokkonen JO, Vartiainen M, Kovanen PT: Low density lipoprotein degradation by secretory granules of rat mast cells: sequential degradation of apolipoprotein B by granule chymase and carboxypeptidase A. J Biol Chem 1986, 261:16067-16072

19. Kokkonen JO, Kovanen PT: Proteolytic enzymes of mast cell granules degrade low density lipoproteins and promote their granulemediated uptake by macrophages in vitro. J Biol Chem 1989, 264 10749-10755

20. Schissel SL, Jiang X, Tweedie-Hardman J, Jeong T, Camejo EH, Najib J, Rapp JH, Williams KJ, Tabas I: Secretory sphingomyelinase, a product of the acid sphingomyelinase gene, can hydrolyze atherogenic lipoproteins at neutral $\mathrm{pH}$ : implications for atherosclerotic lesion development. J Biol Chem 1998, 273:2738-2746

21. Sato H, Kato R, Isogai $Y$, Saka G, Ohtsuki M, Taketomi $Y$, Yamamoto K, Tsutsumi K, Yamada J, Masuda S, Ishikawa Y, Ishii T, Kobayashi T, Ikeda K, Taguchi R, Hatakeyama S, Hara S, Kudo I, Itabe H, Murakami M: Analyses of group III secreted phospholipase A2 transgenic mice reveal potential participation of this enzyme in plasma lipoprotein modification, macrophage foam cell formation, and atherosclerosis. J Biol Chem 2008, 283:33483-33497

22. Bostrom MA, Boyanovsky BB, Jordan CT, Wadsworth MP Taatjes DJ, de Beer FC, Webb NR: Group v secretory phospholipase A2 promotes atherosclerosis: evidence from genetically altered mice. Arterioscler Thromb Vasc Biol 2007, 27:600-606

23. Webb NR, Bostrom MA, Szilvassy SJ, van der Westhuyzen DR, Daugherty A, de Beer FC: Macrophage-expressed group IIA secretory phospholipase A2 increases atherosclerotic lesion formation in LDL receptor-deficient mice. Arterioscler Thromb Vasc Biol 2003, 23:263-268

24. Sartipy P, Johansen B, Camejo G, Rosengren B, Bondjers G, HurtCamejo E: Binding of human phospholipase A2 type II to proteoglycans: differential effect of glycosaminoglycans on enzyme activity. J Biol Chem 1996, 271:26307-26314

25. Torzewski M, Suriyaphol P, Paprotka K, Spath L, Ochsenhirt V, Schmitt A, Han SR, Husmann M, Gerl VB, Bhakdi S, Lackner KJ: Enzymatic modification of low-density lipoprotein in the arterial wall: a new role for plasmin and matrix metalloproteinases in atherogenesis. Arterioscler Thromb Vasc Biol 2004, 24:2130-2136

26. Sneck M, Nguyen SD, Pihlajamaa T, Yohannes G, Riekkola ML, Milne R, Kovanen PT, Oorni K: Conformational changes of apoB100 in SMase-modified LDL mediate formation of large aggregates at acidic pH. J Lipid Res 2012, 53:1832-1839

27. Flood C, Gustafsson M, Pitas RE, Arnaboldi L, Walzem RL, Boren J: Molecular mechanism for changes in proteoglycan binding on compositional changes of the core and the surface of low-density 
lipoprotein-containing human apolipoprotein B100. Arterioscler Thromb Vasc Biol 2004, 24:564-570

28. Chao FF, Blanchette-Mackie EJ, Tertov VV, Skarlatos SI, Chen YJ, Kruth HS: Hydrolysis of cholesteryl ester in low density lipoprotein converts this lipoprotein to a liposome. J Biol Chem 1992, 267:4992-4998

29. Guarino AJ, Tulenko TN, Wrenn SP: Sphingomyelinase-to-LDL molar ratio determines low density lipoprotein aggregation size: biological significance. Chem Phys Lipids 2006, 142:33-42

30. Guarino AJ, Tulenko TN, Wrenn SP: Cholesterol crystal nucleation from enzymatically modified low-density lipoproteins: combined effect of sphingomyelinase and cholesterol esterase. Biochemistry 2004, 43:1685-1693

31. Öörni K, Posio P, Ala-Korpela M, Jauhiainen M, Kovanen PT: Sphingomyelinase induces aggregation and fusion of small very lowdensity lipoprotein and intermediate-density lipoprotein particles and increases their retention to human arterial proteoglycans. Arterioscler Thromb Vasc Biol 2005, 25:1678-1683

32. Grosheva I, Haka AS, Qin C, Pierini LM, Maxfield FR: Aggregated LDL in contact with macrophages induces local increases in free cholesterol levels that regulate local actin polymerization. Arterioscler Thromb Vasc Biol 2009, 29:1615-1621

33. Allahverdian S, Pannu PS, Francis GA: Contribution of monocytederived macrophages and smooth muscle cells to arterial foam cell formation. Cardiovasc Res 2012, 95:165-172

34. Singh RK, Barbosa-Lorenzi VC, Lund FW, Grosheva I, Maxfield FR, Haka AS: Degradation of aggregated LDL occurs in complex extracellular sub-compartments of the lysosomal synapse. J Cell Sci 2016, 129:1072-1082

35. Duewell P, Kono H, Rayner KJ, Sirois CM, Vladimer G, Bauernfeind FG, Abela GS, Franchi L, Nunez G, Schnurr M, Espevik T, Lien E, Fitzgerald KA, Rock KL, Moore KJ, Wright SD, Hornung V, Latz E: NLRP3 inflammasomes are required for atherogenesis and activated by cholesterol crystals. Nature 2010, 464:1357-1361

36. Rajamäki K, Lappalainen J, Öörni K, Välimäki E, Matikainen S, Kovanen PT, Eklund KK: Cholesterol crystals activate the NLRP3 inflammasome in human macrophages: a novel link between cholesterol metabolism and inflammation. PLoS One 2010, 5:e11765

37. Estruch M, Rajamäki K, Sanchez-Quesada JL, Kovanen PT, Öörni K, Benitez S, Ordonez-Llanos J: Electronegative LDL induces priming and inflammasome activation leading to IL-1beta release in human monocytes and macrophages. Biochim Biophys Acta 2015, 1851:1442-1449

38. Rajamäki K, Mäyränpää MI, Risco A, Tuimala J, Nurmi K, Cuenda A, Eklund KK, Öörni K, Kovanen PT: p38delta MAPK: a novel regulator of NLRP3 inflammasome activation with increased expression in coronary atherogenesis. Arterioscler Thromb Vasc Biol 2016, 36:1937-1946

39. Liu-Wu Y, Hurt-Camejo E, Wiklund O: Lysophosphatidylcholine induces the production of IL-1beta by human monocytes. Atherosclerosis 1998, 137:351-357

40. Dasu MR, Jialal I: Free fatty acids in the presence of high glucose amplify monocyte inflammation via Toll-like receptors. Am J Physiol Endocrinol Metab 2011, 300:E145-E154

41. Deerinck TJ, Bushong E, Thor A, Ellisman MH: NCMIR methods for 3D EM: a new protocol for preparation of biological specimens for serial block-face SEM. Microscopy 2010:6-8

42. Kremer A, Lippens S, Bartunkova S, Asselbergh B, Blanpain C, Fendrych M, Goossens A, Holt M, Janssens S, Krols M, Larsimont JC, Mc Guire C, Nowack MK, Saelens X, Schertel A, Schepens B, Slezak M, Timmerman V, Theunis C, VAN Brempt R, Visser Y, Guerin CJ: Developing 3D SEM in a broad biological context. J Microsc 2015, 259:80-96

43. Mastronarde DN: Automated electron microscope tomography using robust prediction of specimen movements. J Struct Biol 2005, 152: $36-51$

44. Kremer JR, Mastronarde DN, McIntosh JR: Computer visualization of three-dimensional image data using IMOD. J Struct Biol 1996, 116:71-76
45. Belevich I, Joensuu M, Kumar D, Vihinen H, Jokitalo E: Microscopy image browser: a platform for segmentation and analysis of multidimensional datasets. PLoS Biol 2016, 14:e1002340

46. Radding CM, Steinberg D: Studies on the synthesis and secretion of serum lipoproteins by rat liver slices. J Clin Invest 1960, 39: $1560-1569$

47. Sun Y, Xu YH, Du H, Quinn B, Liou B, Stanton L, Inskeep V, Ran H, Jakubowitz P, Grilliot N, Grabowski GA: Reversal of advanced disease in lysosomal acid lipase deficient mice: a model for lysosomal acid lipase deficiency disease. Mol Genet Metab 2014, 112:229-241

48. Lehti S, Käkelä R, Hörkkö S, Kummu O, Helske-Suihko S, Kupari M, Werkkala K, Kovanen PT, Öörni K: Modified lipoproteinderived lipid particles accumulate in human stenotic aortic valves. PLoS One 2013, 8:e65810

49. Folch J, Lees M, Sloane Stanley GH: A simple method for the isolation and purification of total lipids from animal tissues. J Biol Chem 1957, 226:497-509

50. Haimi P, Uphoff A, Hermansson M, Somerharju P: Software tools for analysis of mass spectrometric lipidome data. Anal Chem 2006, 78 : 8324-8331

51. Nguyen SD, Öörni K, Lee-Rueckert M, Pihlajamaa T, Metso J, Jauhiainen M, Kovanen PT: Spontaneous remodeling of HDL particles at acidic $\mathrm{pH}$ enhances their capacity to induce cholesterol efflux from human macrophage foam cells. J Lipid Res 2012, 53: $2115-2125$

52. Scifo E, Szwajda A, Soliymani R, Pezzini F, Bianchi M, Dapkunas A, Debski J, Uusi-Rauva K, Dadlez M, Gingras AC, Tyynela J, Simonati A, Jalanko A, Baumann MH, Lalowski M: Proteomic analysis of the palmitoyl protein thioesterase 1 interactome in SH-SY5Y human neuroblastoma cells. J Proteomics 2015, 123: $42-53$

53. Katz SS, Shipley GG, Small DM: Physical chemistry of the lipids of human atherosclerotic lesions: demonstration of a lesion intermediate between fatty streaks and advanced plaques. J Clin Invest 1976, 58 : 200-211

54. Bauernfeind FG, Horvath G, Stutz A, Alnemri ES, MacDonald K, Speert D, Fernandes-Alnemri T, Wu J, Monks BG, Fitzgerald KA, Hornung V, Latz E: Cutting edge: NF-kappaB activating pattern recognition and cytokine receptors license NLRP3 inflammasome activation by regulating NLRP3 expression. J Immunol 2009, 183: 787-791

55. Ståhlman M, Davidsson $P$, Kanmert I, Rosengren B, Boren J, Fagerberg B, Camejo G: Proteomics and lipids of lipoproteins isolated at low salt concentrations in $\mathrm{D} 2 \mathrm{O} /$ sucrose or in $\mathrm{KBr}$. J Lipid Res 2008, 49:481-490

56. Davidsson P, Hulthe J, Fagerberg B, Camejo G: Proteomics of apolipoproteins and associated proteins from plasma high-density lipoproteins. Arterioscler Thromb Vasc Biol 2010, 30:156-163

57. Vaisar T, Pennathur S, Green PS, Gharib SA, Hoofnagle AN, Cheung MC, Byun J, Vuletic S, Kassim S, Singh P, Chea H, Knopp RH, Brunzell J, Geary R, Chait A, Zhao XQ, Elkon K, Marcovina S, Ridker P, Oram JF, Heinecke JW: Shotgun proteomics implicates protease inhibition and complement activation in the antiinflammatory properties of HDL. J Clin Invest 2007, 117: $746-756$

58. Ylä-Herttuala S, Palinski W, Butler SW, Picard S, Steinberg D, Witztum JL: Rabbit and human atherosclerotic lesions contain IgG that recognizes epitopes of oxidized LDL. Arterioscler Thromb 1994, 14:32-40

59. Kockx M, Jessup W, Kritharides L: Regulation of endogenous apolipoprotein E secretion by macrophages. Arterioscler Thromb Vasc Biol 2008, 28:1060-1067

60. Asatryan L, Hamilton RT, Isas JM, Hwang J, Kayed R, Sevanian A: LDL phospholipid hydrolysis produces modified electronegative particles with an unfolded apoB-100 protein. J Lipid Res 2005, 46: $115-122$ 
61. Chao FF, Blanchette-Mackie EJ, Chen YJ, Dickens BF, Berlin E, Amende LM, Skarlatos SI, Gamble W, Resau JH, Mergner WT, Kruth HS: Characterization of two unique cholesterol-rich lipid particles isolated from human atherosclerotic lesions. Am J Pathol 1990, 136:169-179

62. Tailleux A, Torpier G, Caron B, Fruchart JC, Fievet C: Immunological properties of apoB-containing lipoprotein particles in human atherosclerotic arteries. J Lipid Res 1993, 34:719-728

63. Simionescu N, Vasile E, Lupu F, Popescu G, Simionescu M: Prelesional events in atherogenesis: accumulation of extracellular cholesterol-rich liposomes in the arterial intima and cardiac valves of the hyperlipidemic rabbit. Am J Pathol 1986, 123:109-125

64. Filip DA, Nistor A, Bulla A, Radu A, Lupu F, Simionescu M: Cellular events in the development of valvular atherosclerotic lesions induced by experimental hypercholesterolemia. Atherosclerosis 1987, 67:199-214

65. Nievelstein PF, Fogelman AM, Mottino G, Frank JS: Lipid accumulation in rabbit aortic intima 2 hours after bolus infusion of low density lipoprotein: a deep-etch and immunolocalization study of ultrarapidly frozen tissue. Arterioscler Thromb 1991, 11:1795-1805

66. Bocan TM, Schifani TA, Guyton JR: Ultrastructure of the human aortic fibrolipid lesion: formation of the atherosclerotic lipid-rich core. Am J Pathol 1986, 123:413-424

67. Pasquinelli G, Preda P, Vici M, Gargiulo M, Stella A, D'Addato M, Laschi R: Electron microscopy of lipid deposits in human atherosclerosis. Scanning Microsc 1989, 3:1151-1159

68. Guyton JR, Klemp KF: The lipid-rich core region of human atherosclerotic fibrous plaques: prevalence of small lipid droplets and vesicles by electron microscopy. Am J Pathol 1989, 134:705-717

69. Lupu F, Danaricu I, Simionescu N: Development of intracellular lipid deposits in the lipid-laden cells of atherosclerotic lesions: a cytochemical and ultrastructural study. Atherosclerosis 1987, 67:127-142
70. Konikoff FM, Chung DS, Donovan JM, Small DM, Carey MC: Filamentous, helical, and tubular microstructures during cholesterol crystallization from bile: evidence that cholesterol does not nucleate classic monohydrate plates. J Clin Invest 1992, 90:1155-1160

71. Mani V, Hollis JH, Gabler NK: Dietary oil composition differentially modulates intestinal endotoxin transport and postprandial endotoxemia. Nutr Metab (Lond) 2013, 10:6

72. Kozarov EV, Dorn BR, Shelburne CE, Dunn WA Jr, ProgulskeFox A: Human atherosclerotic plaque contains viable invasive Actinobacillus actinomycetemcomitans and Porphyromonas gingivalis. Arterioscler Thromb Vasc Biol 2005, 25:e17-e18

73. Babelova A, Moreth K, Tsalastra-Greul W, Zeng-Brouwers J, Eickelberg O, Young MF, Bruckner P, Pfeilschifter J, Schaefer RM, Grone HJ, Schaefer L: Biglycan, a danger signal that activates the NLRP3 inflammasome via toll-like and P2X receptors. J Biol Chem 2009, 284:24035-24048

74. Tsuzaki M, Guyton G, Garrett W, Archambault JM, Herzog W, Almekinders L, Bynum D, Yang X, Banes AJ: IL-1 beta induces COX2, MMP-1, -3 and -13, ADAMTS-4, IL-1 beta and IL-6 in human tendon cells. J Orthop Res 2003, 21:256-264

75. Beltrami-Moreira M, Vromman A, Sukhova GK, Folco EJ, Libby P: Redundancy of IL-1 isoform signaling and its implications for arterial remodeling. PLoS One 2016, 11:e0152474

76. Sagulenko V, Thygesen SJ, Sester DP, Idris A, Cridland JA, Vajjhala PR, Roberts TL, Schroder K, Vince JE, Hill JM, Silke J, Stacey KJ: AIM2 and NLRP3 inflammasomes activate both apoptotic and pyroptotic death pathways via ASC. Cell Death Differ 2013, 20: $1149-1160$

77. Dai J, Tian J, Hou J, Xing L, Liu S, Ma L, Yu H, Ren X, Dong N, Yu B: Association between cholesterol crystals and culprit lesion vulnerability in patients with acute coronary syndrome: an optical coherence tomography study. Atherosclerosis 2016, 247:111-117 